\title{
Research on Electric Drive for Small Vehicles
}

\author{
Mihail Hristov Antchev and Hristo Mihailov Antchev \\ Section Power Electronics, Technical University-Sofia, Sofia 1000, Bulgaria
}

Received: March 08, 2015 / Accepted: May 06, 2015 / Published: July 31, 2015.

\begin{abstract}
This paper presents an electric drive system whose motor is connected to a battery by means of a buck DC/DC converter. This motor is further connected to an ultracapacitor by means of a boost DC/DC converter. First, operation and break processes are studied when the converters are switched off as well as when they are switched on in current limitation mode. Then, a comparative analysis of the results in the two operation modes is done.
\end{abstract}

Key words: Ultracapacitor, regenerative breaking, power converter.

\section{Introduction}

Research and applications of different storage and supply elements are presented in contemporary electrical and hybrid vehicles power supply's systems. Ref. [1] presents a bidirectional buck/boost converter, as the start energy is supplied by ultracapacitor discharge and, during the breaking, the energy charges the ultracapacitor. A control and regulation system is presented as well. The power supply is provided by a supply grid. Similar research is done in Ref. [2], as the supply comes from a three-phase electrical grid. Ref. [3] describes a bidirectional buck/boost three-level DC/DC converter used together with an ultracapacitor. Ref. [4] reviews several configurations of battery and ultracapacitor connections with different possibilities of energy exchange. The presented solutions use AC electric drive and an inverter. Ref. [5] describes again a bidirectional converter. In Ref. [6], two bidirectional converters are connected to the DC bus of the photovoltaic system: the first one for the $\mathrm{Li}$-ion battery and the other one for the ultracapacitor. Ref. [7] uses again a DC bus and presents a hybrid system. The bidirectional DC/DC galvanic isolation converter supplied by supercapacitors and fuel cells are

Corresponding author: Mihail Hristov Antchev, professor, DSc. (doctor of science), research fields: power electronics and control systems. E-mail: antchev@tu-sofia.bg. presented in Ref. [8]. Similar research is shown in Ref. [9], where a battery and fuel cell is used. Ref. [10] describes a three-level bidirectional converter for fuel-cell/battery hybrid power system. Part of the research is dedicated to the control systems. The particularities of the control and a new control method for a hybrid system with ultracapacitor for electric drive are presented in Ref. [11]. Ref. [12] uses predictive control in a system with fuel cell and describes hybrid system with numeric control [13]. Other types of converters for hybrid systems are presented in Ref. [14].

The analysis of recent studies demonstrates that different storage and supply elements are used in different systems. According to the principle of energy consumption, power electronic devices circuits and their control methods are synthesized in different modes.

This paper focuses on an entirely electric drive system, containing battery and ultracapacitor. Its operation is based on the following principle: the energy of the battery is used for the operation of the electric drive in energy motoring mode. In breaking mode, energy recuperation of the electric drive is assured by an ultracapacitor. The ultracapacitor supplies a separate drive that is used only in specific moments, for example a short acceleration. 


\section{System Description}

Fig. 1 presents the block diagram of the system. In addition to the electric drive, the storage and supply energy elements (battery and ultracapacitor), it includes a buck DC/DC converter and a boost DC/DC converter. If energy is consumed from the battery, the electric drive operates in motor mode and the buck converter is switched on. In breaking mode, the electric drive operates in generator mode, the boost converter is switched on and energy is supplied to the ultracapacitor. Both converters have a common inductor L. In both modes, the drive current is monitored by a current transducer and can be set by switching on and off the transistors of the control system converters. The used control is hysteresis current control. Current settings change by means of potentiometric pedal. The control system monitors the voltage of the battery and the ultracapacitor, as well as their temperature, in order to assure their optimum mode and protect them from deep discharge or overvoltage.

Fig. 2 presents the power circuit. Q1-Q4 transistors, D9-D12 diodes and L1 inductor are the buck converter elements. Q5 transistor, D21 and D22 diodes and L1 inductor are the boost converter elements. D1-D4 are blocking diodes and prevent any energy reinjection into the battery in breaking mode. Q6 transistor has analogical function with regards to the ultracapacitor in energy regenerating mode. When the buck converter is switched on Q6 is permanently switched off and does not allow for any energy transfer to the ultracapacitor. When the boost converter is switched on Q6 is permanently switched on. Control signals, as

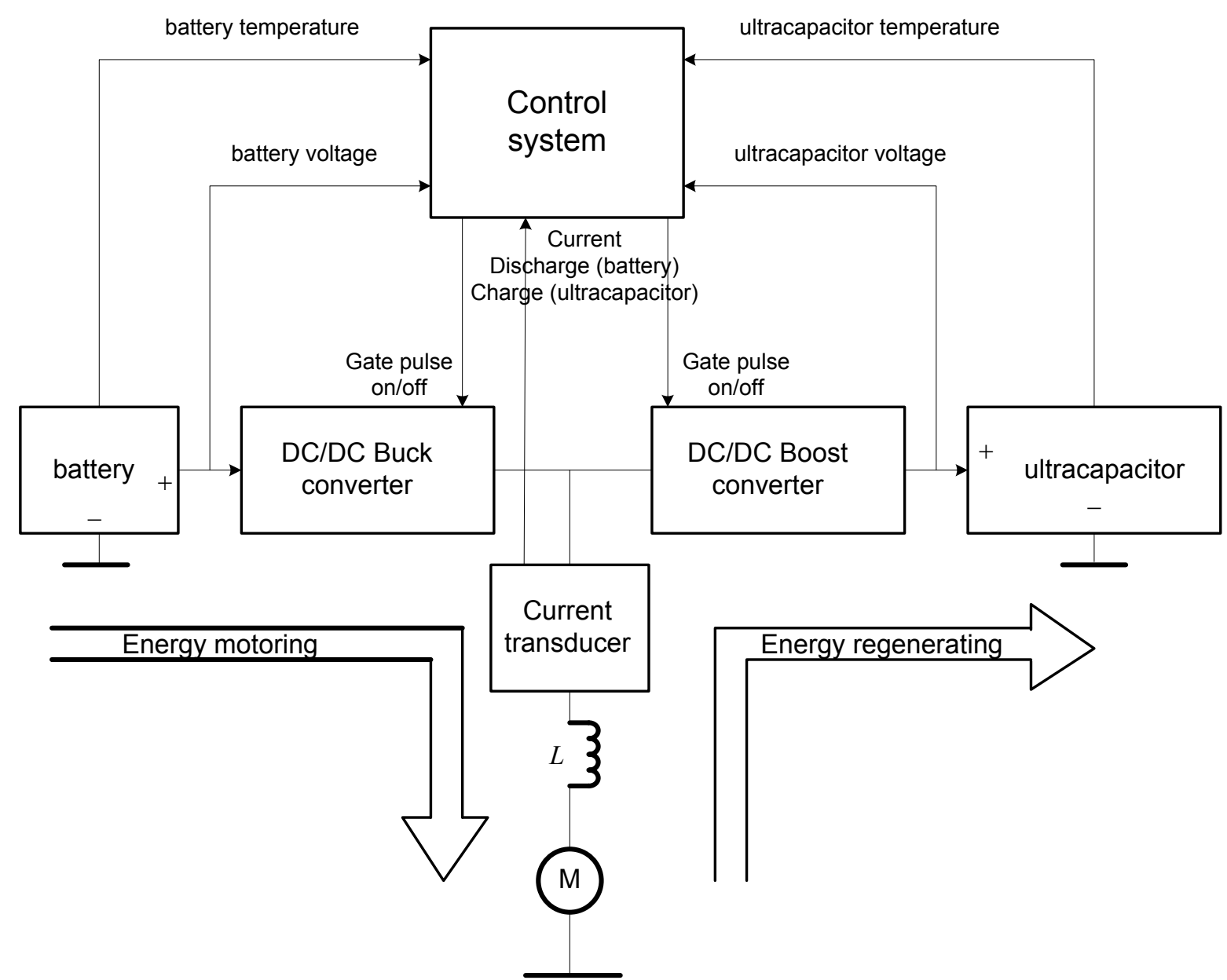

Fig. 1 Block diagram of the regenerative breaking electric drive system. 


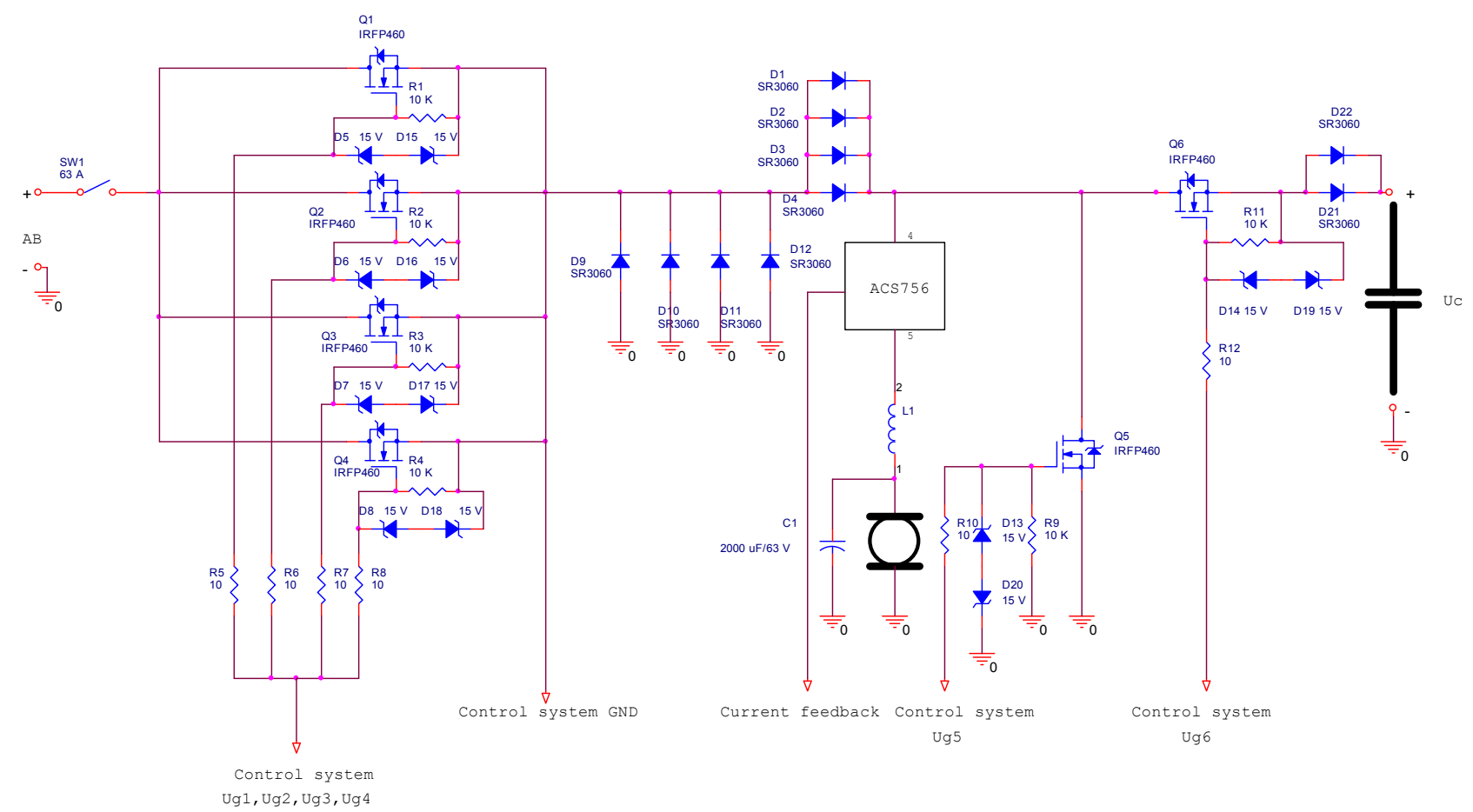

Fig. 2 Power converters circuit.

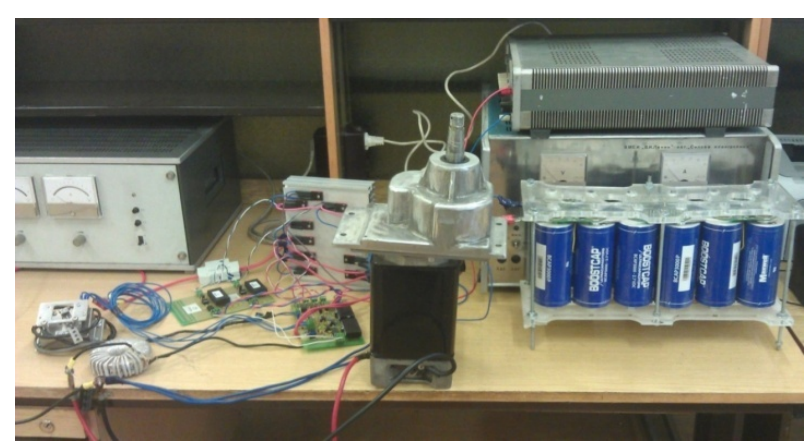

Fig. 3 Experimental research model.

well as current feedback for the control and regulation system are shown.

\section{Experimental Results}

The electric drive used for the experimental research has the following characteristics: power supply voltage $24 \mathrm{~V}$ and no load operation-2,000 rpm. At load and 1,800 rpm, the current consumption is 38 A. The battery is a Li-ion battery $36 \mathrm{~V} / 10 \mathrm{Ah}$. The ultracapacitors are BCAP3000P type-3,000 F, $2.7 \mathrm{~V}$ of Maxwell Technologies [15]. Twelve series

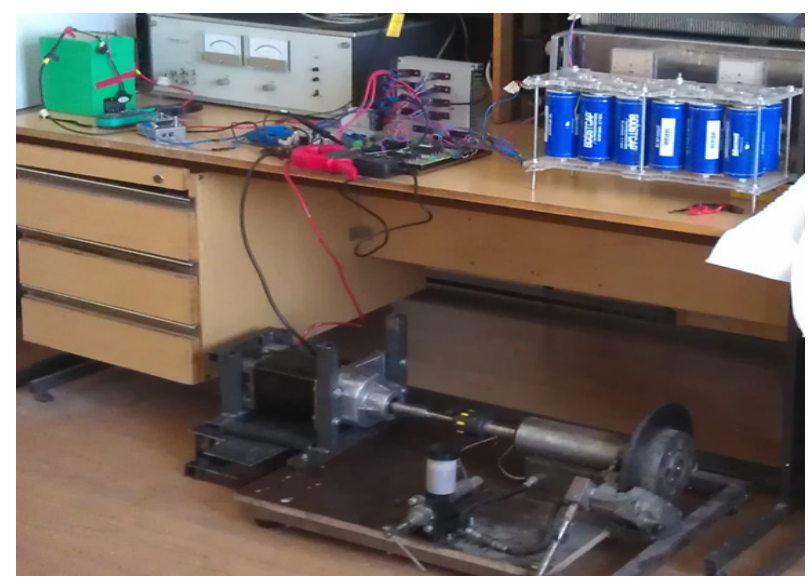

connected ultracapacitors are used for the experiment. The total capacity is $250 \mathrm{~F}$ and voltage is $32.4 \mathrm{~V}$. Voltage equalizers are connected between each two capacitors. Fig. 3 shows the experimental model.

Figs. 4 and 5 presented research result diagrams. $\mathrm{CH} 1$ shows the drive voltage. The voltage probe is $1: 1$. $\mathrm{CH} 2$ shows the L-inductor current. The current probe is $10 \mathrm{~mA} / \mathrm{mV}$. In Fig. 4, one can see these value variations at no current limitation start and at breaking with the boost converter switched off. In Fig. 5, the same values, at current limitation start and at breaking 


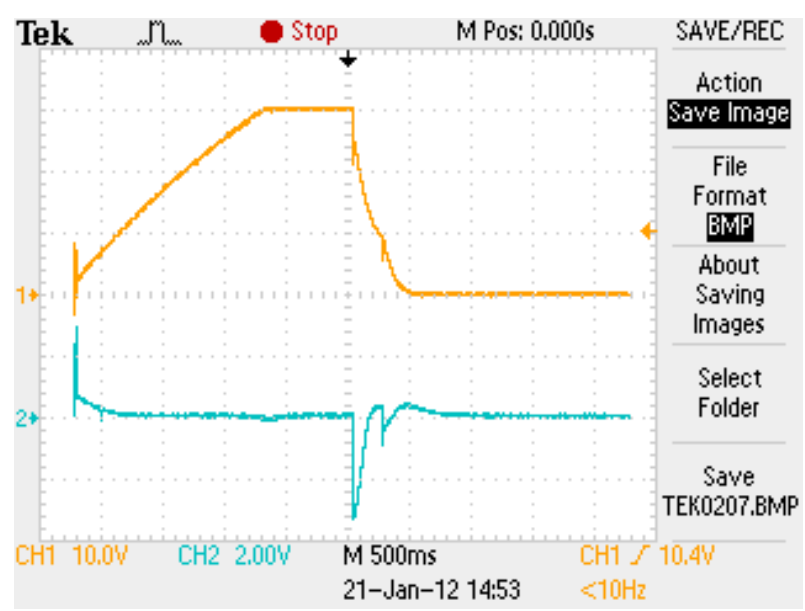

(a)

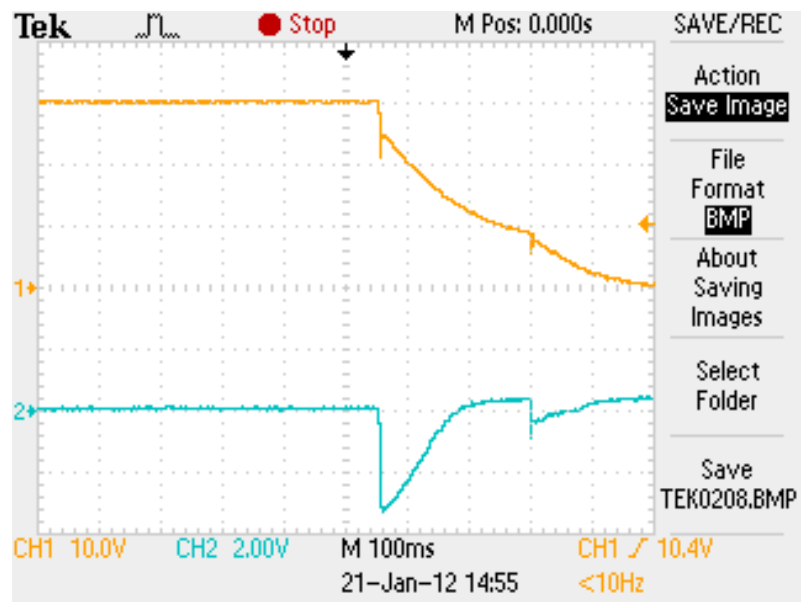

(b)

Fig. 4 (a) No current limitation start and breaking with boost converter switched off- $500 \mathrm{~ms} / \mathrm{div}$; (b) breaking with boost converter switched off- $100 \mathrm{~ms} / \mathrm{div}$.

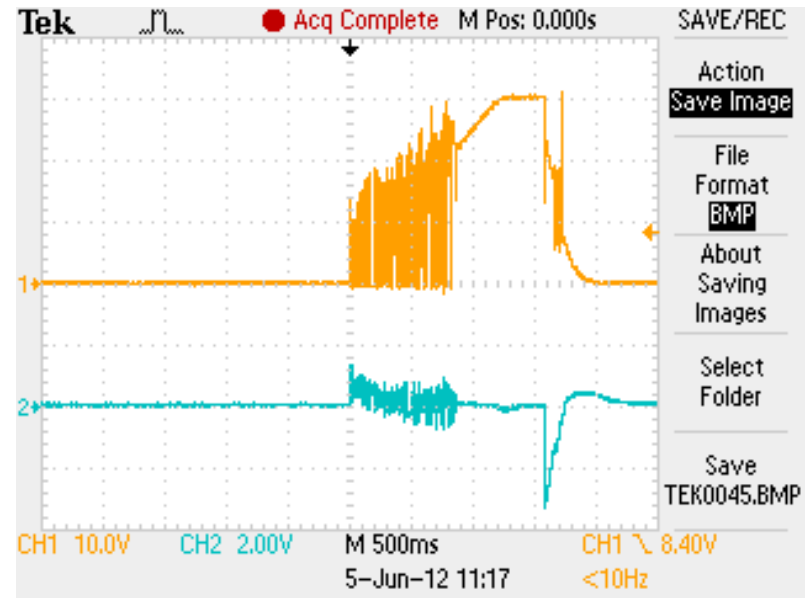

(a)

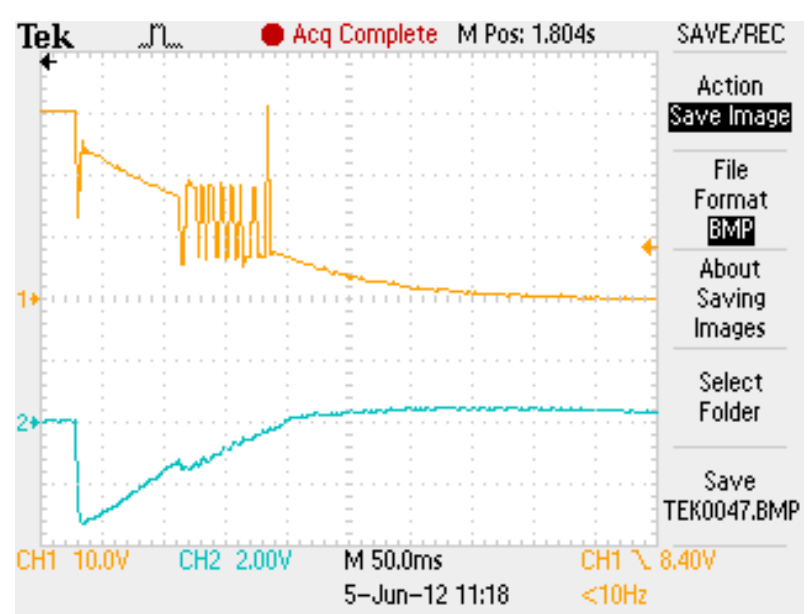

(b)

Fig. 5 (a) Current limitation start and breaking with boost converter switched on-500 ms/div; (b) breaking with boost converter switched on-50 ms/div.

with the boost converter switched on, also with current limitation.

The presented diagrams show the following particularities of the start mode. First, the current limitation start assures a soft start as well as the possibility to set the motor rpm in energy motoring mode by way of limiting current variation. The comparison of the diagrams of Figs. 4 and 5 reveals that, in the case of current limitation start, one can avoid the higher value of the start current at initial start proper to Fig. 4, without current limitation.

The sum of the areas of the two triangles of Fig. 4 is approximately $4.5 \mathrm{~A} \cdot \mathrm{s}$. Similarly from the current diagram of Fig. 5 is obtained approximately $5.5 \mathrm{~A} \cdot \mathrm{s}$.

\section{Conclusions}

This paper presents an electric drive system whose motor is connected to a battery by means of a buck DC/DC converter. This motor is further connected to an ultracapacitor by means of a boost $\mathrm{DC} / \mathrm{DC}$ converter. This study focuses on the operation of the system during the start of the drive at energy motoring mode with regulation of the limitation current of the buck converter. This result in lower initial start current and a possibility to regulate start rpm. Another part of the research focuses on regenerative breaking mode 
with current limitation of the boost converter. This results in a $20 \%$ higher value of the product ultracapacitor charge current and charge time, than in case of a boost converter switched off. The system can be used for small vehicles.

\section{References}

[1] Iannuzzi, D., and Tricoli, P. 2012. "Speed-Based State-of-Charge Tracking Control for Metro Trains with Onboard Supercapacitors." IEEE TPE 27 (4): 2129-40.

[2] Grbovic, P. J., Delarue, P., Le Moigne, P., and Bartholomeus, P. 2011. "Modeling and Control of the Ultracapacitor-Based Regenerative Controlled Electric Drives." IEEE TIE 58 (8): 3471-84.

[3] Graovic, P. J., Delarue, P., Le Moigne, P., and Bartholomeus, P. 2011. "The Ultracapacitor-Based Controlled Electric Drives with Braking and Ride-Through Capability: Overview and Analysis.” IEEE TIE 58 (3): 925-36.

[4] Cao, J., and Emadi, A. 2012. "A New Battery/Ultracapacitor Hybrid Energy Storage System for Electric, Hybrid, and Plug-in Hybrid Electric Vehicles." IEEE TPE 27 (1): 122-32.

[5] Naayagi, R. T., and Forsyth, A. J. 2010. "Bidirectrional DC/DC Converter for Aircraft Electric Energy Storage System." In Proceedings of the 5th IET Int. Conf. Power Electronics, Mashines and Drives, PEMD, 1-6.

[6] Ongaro, F., Saggini, S., and Mattaveli, P. 2012. "Li-ion Battery-Supercapacitor Hybrid Storage System for a Long Lifetime, Photovoltaic-Based Wireless Sensor Network." IEEE TPE 27 (9): 3044-952.
[7] Thounthong, P., Real, S., and Davat, B. 2006. "DC Bus Voltage Regulation Supplied by Fuel Cell/Supercapacitor Hybrid Source." ECTI Trans. of Electrical Engeneering, Electronics and Communications 4 (2): 90-5.

[8] Zhang, Z., Ouyang, Z., Thomsen, O., and Andersen, M. 2012. "Analysis and Design of a Bidirectional Isolated DC-DC Converter for Fuel Cells and Supercapacitors Hybrid System." IEEE TPE 27 (2): 848-59.

[9] Wai, R., Jhung, S., Liaw, J., and Chang, Y. 2013. "Intelligent Optimal Energy management System for Hybrid Power Sources Including Fuel Cell and Battery." IEEE TPE 28 (7): 3231-44.

[10] Jin, K., Yang, M., Ruan, X., and Xu, M. 2010. "Three-Level Bidirectional Converter for Fuel-Cell/Battery Hybrid Power System." IEEE TIE 57 (6): 1976-86.

[11] Camara, M. B., Gualous, H., Gustin, F., Berthon, A., and Dakyo, B. 2010. "DC/DC Converter Design for Supercapacitor and Battery Power Management in Hybrid Vehicle Applications-Polynomial Control Strategy." IEEE TIE 57 (2): 587-97.

[12] Greenwell, W., and Vahidi, A. 2010. "Predictive Control of Voltage and Current in a Fuel Cell-Ultracapacitor Hybrid." IEEE TIE 57 (6): 1954-63.

[13] Jian, Z., Dougal, R. A. 2006. "A Compact Digitally Controlled Fuel Cell/Battery Hybrid Power Source." IEEE TIE 53 (4): 1094-104.

[14] Gui-Jia, S., and Tang, L. 2008. "A Multiphase, Modular, Bidirectional, Triple-Voltage DC-DC Converter for Hybrid and Fuel Cell Vehicle Power Systems." IEEE TPE 23 (6): 3035-46.

[15] Maxwell Technologies. "K2 Series Ultracapacitors." Maxwell Technologies, Document Number: 1015370.3. Accessed March 08, 2015, http://www.maxwell.com. 